\title{
Gamification 101:
}

\section{An Introduction to the Use of Game Dynamics to Influence Behavior}

\section{TABLE OF CONTENTS}

Introduction

Section I: Gamification Defined

- A brief overview of the terms, concepts, and history

Section II: The Business Value of Gamification

- How and why it works; examples of its use

Section III: The Building Blocks of Gamification

- The elements involved in creating a successful experience

Section IV: Summary and Next Steps

- Where to go from here?

Section V: About Bunchball and Nitro

- A brief look at the company and its offerings

Acknowledgements

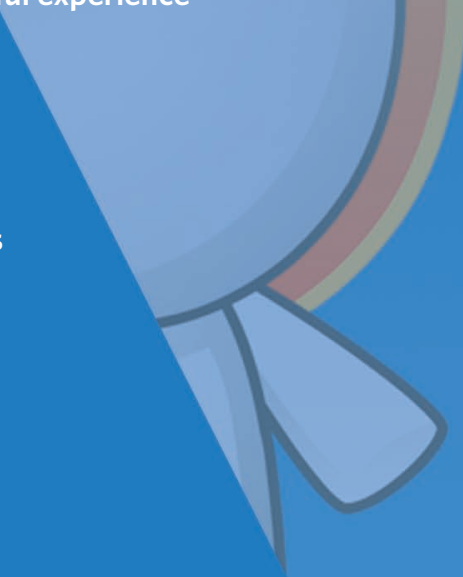

When your customers participate, your business wins!

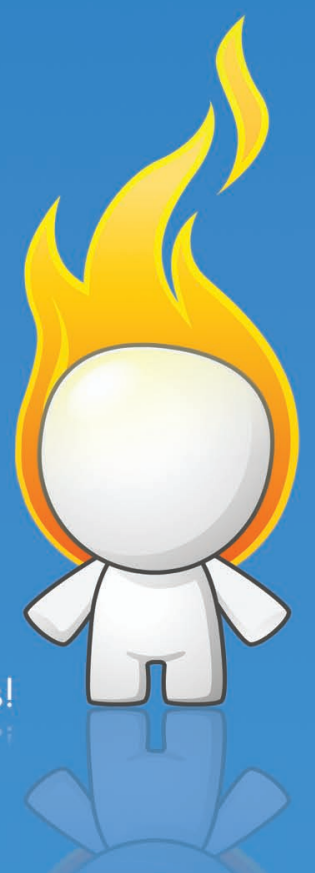




\section{Gamification 101: An Introduction to the Use of Game Dynamics to Influence Behavior}

\author{
ga.mi-fi-ca·tion [gay-muh-fi-kay-shuhn] \\ integrating game dynamics into your site, \\ service, community, content or campaign, \\ in order to drive participation.
}

\section{INTRODUCTION}

Why Should You Care?

Gamification - applying the mechanics of gaming to nongame activities to change people's behavior - is an important and powerful new strategy for influencing and motivating groups of people. The business community is just starting to realize the power it has to improve customer engagement, build loyalty, and incent employees and partners to perform at high levels. And the concept has the potential to solve a variety of problems outside the business world as well, in areas such as:

- Health \& Wellness: healthcare cost containment, obesity programs, smoking cessation...

- Education \& Training: e-learning, corporate and vocational training, online testing...

- Public Policy \& Government: education reform, climate change, welfare reform...

But beware of the hype! As with many new and promising technologies, there are already a lot of pundits who have jumped on the gamification bandwagon and hyperbole is flying. Simply Googling the word "gamification" brings up articles and videos with titles like "Gaming Can Make A Better World," "The Gamification of Life," and "The Gamification of Everything."

Understanding how and why gamification works, in what contexts it is most effective, and what the limits are of this approach will be highly useful in sorting out the useful bits. This report will help provide a basic foundation and definition for the concept of gamification. We plan to extend and build upon this foundation as we try to help move gamification from an art to a science. Please let us know what you think of this whitepaper by sending us an email at gamification101@bunchball.com.

\section{GAMIFICATION DEFINED}

\section{Definition of Terms}

We'll expand each of the following definitions in greater detail throughout the whitepaper. As an introduction, let's give a brief overview of a few key terms that are central to this paper.

\section{Gamification}

At its root, gamification applies the mechanics of gaming to nongame activities to change people's behavior. When used in a business context, gamification is the process of integrating game dynamics (and game mechanics) into a website, business service, online community, content portal, or marketing campaign in order to drive participation and engagement.

\section{Participation and Engagement}

The overall goal of gamification is to engage people to participate - to share and interact in some activity or community by offering a compelling, dynamic, and sustained gamification experience, and which can be used to accomplish a variety of business goals.

\section{Game Mechanics \& Game Dynamics}

These two terms are closely related and sometimes used interchangeably. For our purposes, game mechanics are the various actions, behaviors, and control mechanisms that are used to "gamify" an activity - the aspects that, taken together, create a compelling, engaging user experience. The compelling, motivational nature of this experience is, in turn, the result of desires and motivations we call game dynamics.
Game mechanics include:

- Points

- Levels

- Challenges

- Virtual goods and spaces

- Leaderboards

- Gifts and charity
Game dynamics include:

- Reward

- Status

- Achievement

- Self-expression

- Competition

- Altruism 


\section{Games Are Everywhere}

Humans have been playing games in various forms since the days of the caveman, and competition is deeply ingrained in the human psyche. Fast forward to the modern era with the significant free time that people have today, and gaming has become a hugely popular and tremendously profitable industry, on the order of $\$ 60$ billion per year. Given this wide acceptance of gaming and the emergence of the internet, people have become more open to game mechanics in other parts of their lives. As a result, "gamification" is becoming a powerful tool through which organizations teach, persuade, and motivate people. Many different activities that people do today incorporate game mechanics - things that you might not think of as games at all. Let's examine a few.

\section{Frequent Flyer Programs}

120 million people around the world are accruing points, leveling up, and earning rewards in the Frequent Flyer Programs (FFPs) offered by nearly every major airline. FFPs are actually complex games, with customers earning miles (points) for every segment flown, moving from Bronze to Silver and Gold status (leveling up), and even completing challenges like "Fly 3 segments in the next 90 days for 2500 bonus miles." And they'll go out of their way to stick with the vendor where they have the most points and status - even when disappointed with the actual service.

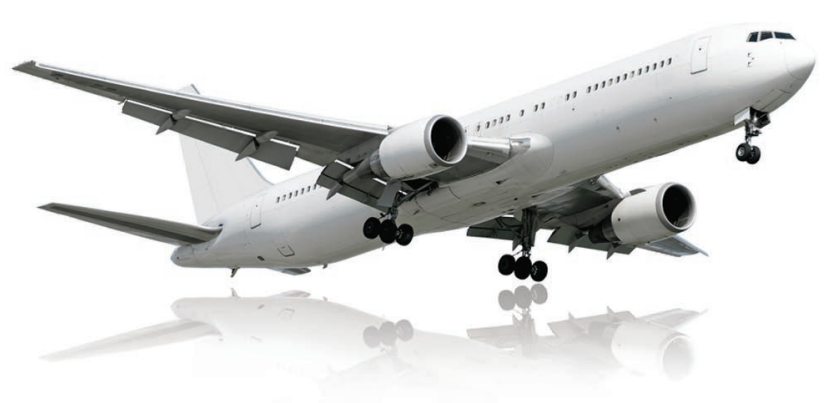

\section{Starbucks and Foursquare}

The world's biggest coffee chain is rewarding users with virtual points and virtual badges for visiting their retail stores. Starbucks, in conjunction with a startup called Foursquare, enables their customers to "check-in" at their retail locations on their mobile phones. And when they do, they earn points and can complete quests, like "visit 5 different
Starbucks," to earn special trophies or badges. The points aren't worth anything, and the badges don't get you anything - they're just using fun to get people to visit Starbucks.

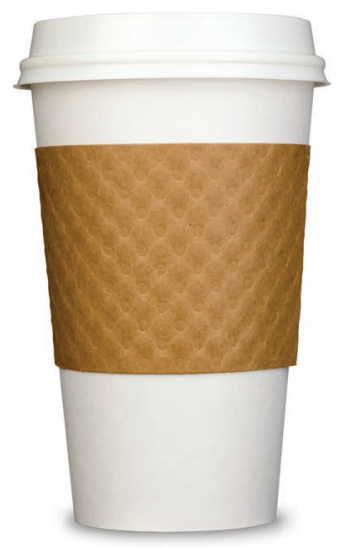

\section{Nike+ and the iPod}

The world's largest manufacturer of athletic footwear and apparel worldwide has "gamified" exercise with the launch of Nike+ in 2008. Over 1.8 million runners are currently using Nike+ to capture data such as distance, pace, and calories burned using a GPS sensor connected to their iPod. The Nike software loaded on the iPod will then "reward" users if they reach a milestone - for example, runners hear Tour de France cycling champ Lance Armstrong congratulating them if they beat their five-mile distance record. After workouts, runners go online to upload their data, track their statistics, set goals, join challenges, play with an online "alter ego," and connect with fellow runners in the Nike community and other social networks. Nike+ has allowed the company to build a huge and active fan base - for instance, over 800,000 runners logged on and signed up when Nike sponsored a 10K race simultaneously across 25 cities.

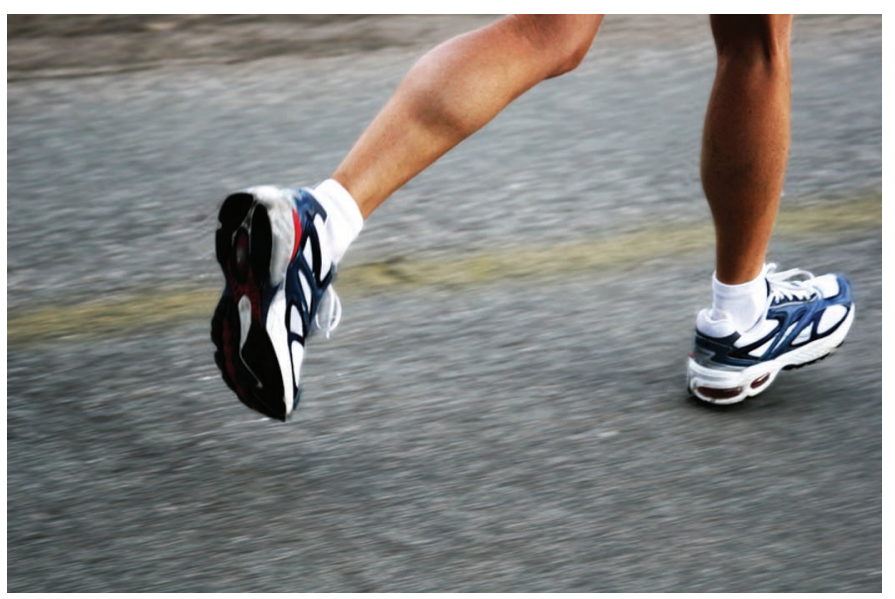




\section{Participation and the IKEA Effect}

"Research conducted with my colleagues Daniel Mochon, of Yale University, and Dan Ariely, of Duke University, shows that labor enhances affection for its results. When people construct products themselves, from bookshelves to Build-a-Bears, they come to overvalue their (often poorly made) creations. We call this phenomenon the IKEA effect, in honor of the wildly successful Swedish manufacturer whose products typically arrive with some assembly required."

- Michael I. Norton, "The IKEA Effect: When Labor Leads to Love," Harvard Business Review - Breakthrough Business Ideas for 2009," February 2009.

\section{THE BUSINESS VALUE OF GAMIFICATION}

\section{Participation Drives Business Value}

Participation builds lasting relationships and impacts fundamental business objectives. When people participate, it means that they're engaged with you, that you're building lasting relationships with them, and that you're impacting your fundamental business objectives. If you can get people to participate, your business wins. But what kind of participation? Gamification can drive virtually any kind of participation, including:

- Watching videos

- Listening to audio

- Viewing photos

- Opting in to email communication

- Creating content

- Answering questions

- Making a purchase

- Taking quizzes

- Searching for information

- Sharing personal info

- Rating products

- Reading articles

- Filling out registration data

- Voting on content

- Writing comments

- Participating in discussions

- Posting to forums

- Taking a poll

- Visiting repeatedly

- Visiting affiliated sites

- Recommending affiliated sites

\section{Tracking Statistics Drives Participation}

At its core, gamification is all about statistics. If two people play Monopoly every day for a week, it's going to get boring pretty quickly. But if they start capturing and displaying statistics - how many times each person won, how many dollars each winner had, which properties were most profitable - then the experience becomes more interesting.

These statistics create another level to the game and motivate people to play more. In essence, the statistics become the game. Can you become the \#1 ranked Monopoly player in your group of friends, in the state, in the country? Can you own Boardwalk and Park Place five games in a row, and thus win a special trophy? Can you earn Monopoly Points for every dollar you end the game with, and collect those points toward some ultimate reward?

By capturing statistics, communicating standings, and rewarding accomplishments, we create a new method to drive participation. Even though individual games (or other activities) may have lost their initial excitement, each episode becomes an entry into a larger game, one that creates a desire to make return visits in order to reach these new goals.

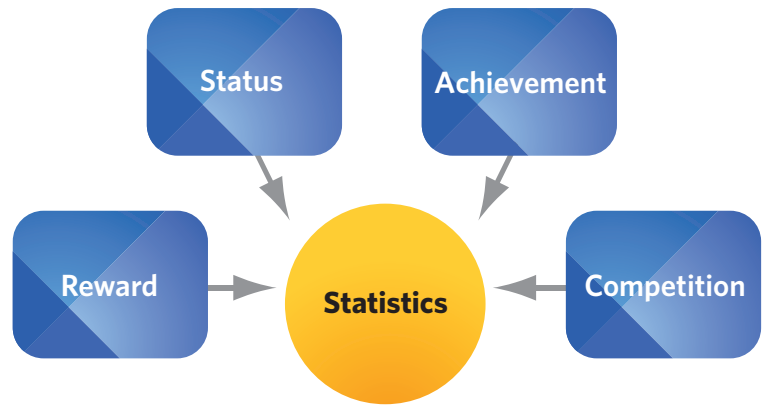


white paper

Gamification 101: An Introduction to the Use of Game Dynamics to Influence Behavior

\section{Who Is Participating?}

Gamification is a strategy for influencing and motivating the behavior of people - any people, whether they are customers, employees, students, fans, constituents, patients, etc. And while it uses techniques from game design, it is not a new way to reach the gamer market. The audience for gamification is anyone you want to engage repeatedly in order to elicit a particular behavior.

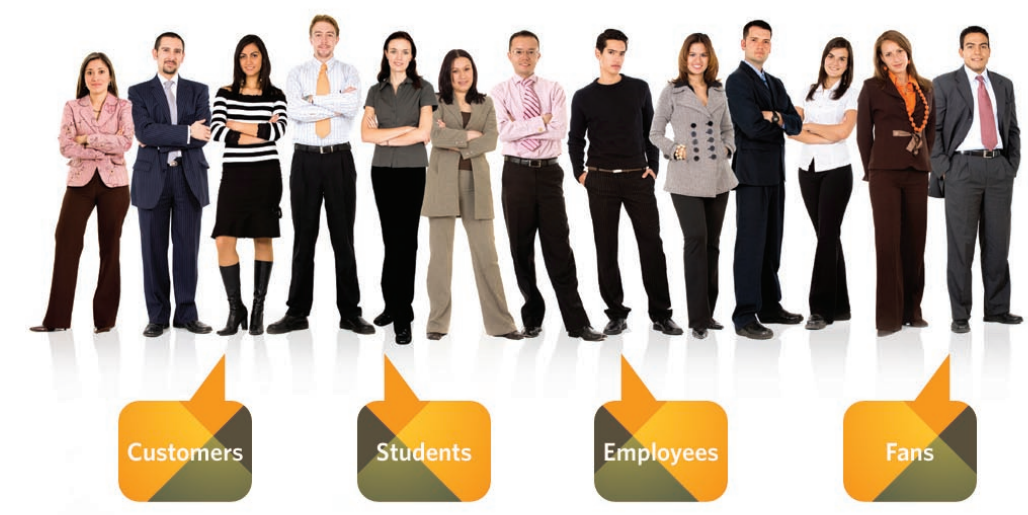

"Companies of all shapes and sizes have begun to use games to revolutionize the way they interact with customers and employees, becoming more competitive and more profitable as a result."

- "Changing the Game", David Edery, Ethan Mollick

\section{Use Cases of Gamification}

The following examples illustrate some of the applications in which gamification can be used to create business value.

\section{Building and activating a community of members or fans}

A common business goal is to pull together and engage a group of people with a common passion or interest, and then to "activate" them to purchase. In particular, many marketers have been looking to leverage online social networking for this purpose, but the results have been mixed. Adam Sarner, an analyst with market research firm Gartner, has projected that over 75 percent of Fortune 1000 companies with Web sites will have undertaken some kind of online social-networking initiative for marketing or customer relations purposes. But 50 percent of those campaigns will be classified as failures. . And Forrester analyst Jeremiah Owyang concludes that "...many brands are wasting their time, money, and resources to reach communities in social networks without first understanding that the use case is very different than a microsite campaign."2

Through gamification, organizations can take back control of the brand experience by engaging users, encouraging them to join a community, driving active participation, sharing with friends outside the community, and even recruiting friends to join the community. Gamification enables you to turn customers into fans, and fans into evangelists.

${ }^{1}$ http://news.cnet.com/8301-13577_3-10058509-36.html

${ }^{2}$ http://www.web-strategist.com/blog/2008/07/18/forrester-report-best-and-worst-ofsocial-network-marketing-2008/ 
white paper

Gamification 101: An Introduction to the Use of Game Dynamics to Influence Behavior

\section{Example: Global Technology Company}

A leading computer manufacturer recently launched a campaign on Facebook to build up a community of college students focused around "tech stuff," with the goal of promotion their educational computing site and sell more student laptops. To drive the growth of this Facebook site, they created a gamified Facebook application that offered students a chance to win a $\$ 5,000$ scholarship and a free PC for a friend. In order to win, students had to earn points and awards for doing things like registering for the contest, inviting a friend to join, creating a team, and registering on the company's educational computing site, and posting contest messages and awards on their wall on Facebook. The result? Six weeks after the launch of the gamified Facebook application, they had increased program participation 10X. Other success metrics from the campaign:

- 1 in 6 participants wrote and submitted an essay (one of their missions)

- Almost 1 in 5 made the student laptop their profile picture on Facebook for a day (one of their missions)

- 1 in 4 recruited their friends to help them (one of their missions)

- 1 in 3 checked out the student laptop reviews (one of their missions)

- 1 in 3 promoted the Facebook application (one of their missions)

- 1 in 3 posted their award and new level

- 1 in 3 visited the educational computing site

\section{Building your brand}

In the long run, the goal of marketing is to maximize the lifetime value of the customer base by increasing the average selling price and frequency of purchase. The traditional way that marketers look at this process is the "purchase funnel," a model which describes the theoretical customer journey from the moment of first contact with your brand (awareness) through product consideration, to the ultimate goal of a purchase. Using gamification, marketers can help increase brand awareness, affinity, and purchase intent by driving their audience to spend more time on a website or related social media property and come back more often. The more users interact with a site, the more valuable and loyal they become and the less incentive they have to click away to another source.

\section{Client Facebook Campaign}

\begin{tabular}{|c|c|c|c|c|}
\hline & Past 8 Weeks & $\begin{array}{l}\text { 3-Week } \\
\text { Trend }\end{array}$ & $\begin{array}{l}\text { Campaign } \\
\text { Total }\end{array}$ & $\begin{array}{l}\text { wow\% } \\
\text { Change }\end{array}$ \\
\hline $\begin{array}{r}\text { Total Microsite } \\
\text { Fans }\end{array}$ & & & 228,192 & $21 \%$ \\
\hline $\begin{array}{r}\text { New Microsite } \\
\text { Fans }\end{array}$ & & & 223,925 & $61 \%$ \\
\hline $\begin{array}{l}\text { Facebook Fan Page } \\
\text { Unique Page Views }\end{array}$ & & & 569,331 & $63.9 \%$ \\
\hline $\begin{array}{r}\text { Facebook Tab } \\
\text { Views }\end{array}$ & & $\Rightarrow$ & 1,899 & $-13.0 \%$ \\
\hline $\begin{array}{r}\text { Selects "Enter" } \\
\text { Button }\end{array}$ & & & 4,072 & $-1.4 \%$ \\
\hline $\begin{array}{r}\text { Total Facebook } \\
\text { Users }\end{array}$ & & 1 & 12,198 & $46.0 \%$ \\
\hline $\begin{array}{r}\text { New Face book } \\
\text { Users }\end{array}$ & & & 3,8401 & $38.1 \%$ \\
\hline
\end{tabular}

\section{Example: Global Consumer Product}

A European consumer and industrial products company made a decision to shift the marketing strategy for one of their top Personal Care products to a "high engagement, online ecosystem" model. The program that came out of this strategy was a social networking application connecting participants across the web and social media. The goal for participants is to earn rewards by completing challenges, such as viewing a series of web pages or playing Flash mini-games on partner sites. The social game has been explicitly designed to encourage longterm engagement of participants, with repeat users earning frequent rewards.

The company created an initial core user base via co-branding with a top-tier North American professional sports league, and then grew the user base using viral game mechanics that motivate participants to invite friends from their social networks. Other game mechanics focus on activating fans, friends, and all others with brand purchases and trials via promotional integration. A microsite serves as the participants' dashboard, providing a central location to customize their avatar, view their progress, accept challenges and engage in social activities. In addition, the experience requires repeat visits to the microsite, strengthening the participant's association with the brand. 


\section{Driving engagement and loyalty}

Loyalty has evolved beyond earning points for purchases to deeper customer engagement. Traditional redemption-focused loyalty programs created clever points systems and offered gifts or discounts in return for purchases. These marketers assumed that the best consumers will "burn" what they've earned, be satisfied with the reward, and come back to the brand in the future. Savvy marketers now realize that they must differentiate themselves from this foundational model, primarily because the rewards given by most loyalty programs offer far less competitive advantage in the age of the internet and global commerce. Using gamification, loyalty programs can significantly increase their effectiveness by adding more intrinsic motivators to the "earn" (points) aspect of the loyalty experience.

Earning points mimics the elements of a game, including competition and the pursuit of a goal. Fun, compelling and addictive game play generates exciting emotions that add to the player's experience, whether the competition is solitary or involves others. An effective loyalty program views the entire "earn" experience as a game, one wherein the "play" is just as fun as the "winning." Adding leaderboards and tieredachievement levels will enhance the gaming aspects because people often desire the challenge of working for a reward. Essentially, the right level of challenge arouses and excites the brain. Setting and hitting milestones result in a repeated sense of accomplishment and boosts self-worth, leading to the ultimate satisfaction of reaching the goal and "winning the game."

\section{Example: Major Entertainment Company}

One of the largest entertainment companies in the world wanted a loyalty system that not only rewarded purchases, but also rewarded participation and engagement with their content, which includes major motion pictures. This program gave points for purchasing Blu-ray and regular DVDs as well as movie tickets. Buyers then redeemed those points for dollar-value products, like more DVDs. In addition, members can earn credits for engaging with their content, like watching movie trailers, visiting movie websites, playing games, and contributing content. By combining offline purchase data with online engagement and participation data, they can now build a detailed profile of each of their customers. The resulting gamification campaign has:

- Increased consumption of promotional content

- Increased user-generated content

- Increased traffic to the individual movie sites

- Increased sale of products

- Developed a 360-degree view of their customers.

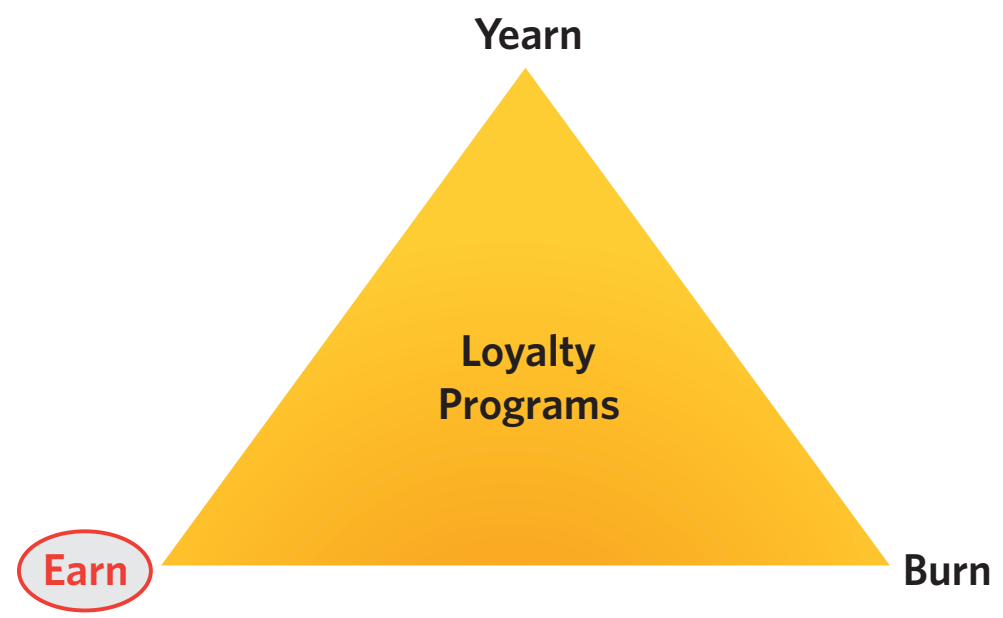

\footnotetext{
${ }^{3}$ Barry Kirk. "A New Paradigm for Loyalty Marketing," Maritz White Paper, August 2010 ,

<http://www.maritz.com/ /media/Files/MaritzDotCom/White\%20Papers/Loyalty/New-Paradigm-Loyalty-Marketing.ashx>
} 
white paper

Gamification 101: An Introduction to the Use of Game Dynamics to Influence Behavior

\section{Motivating behavior}

Wherever there are people, there are people to be motivated.

- Sales people and channel partners can be incented to grow revenues and focus on desired product mixes via competition and challenges.

- Call centers and customer support organizations can be motivated to deliver superior customer service through a customer feedback mechanism or other metrics.

- Employees can be motivated to pursue optional training initiatives that enhance their careers and make them more valuable to the company.

- Patients and health insurance customers can be incented to adopt and stick with healthy lifestyle choices that extend their lives and reduce healthcare costs.

Gamification can be applied across a broad spectrum of situations where individuals need to be motivated or incented to pursue specific actions or activities.

\section{Example: HopeLab}

HopeLab is an innovative organization whose mission is to drive positive health behavior in young people. Fighting chronic illnesses like cancer, obesity, and depression, HopeLab uses games and connected devices to create the most effective motivational methods. For example, the Zamzee device is worn on a belt or carried in a pocket, and it monitors physical activity throughout the day. Plugging it into a computer, this data is converted to points that can be redeemed for virtual goods and real-world rewards, including the ability to donate to a cause. Though the product is still under development, a pilot study showed that kids using the Zamzee device and website were about $30 \%$ more active than those who did not. 


\section{THE BUILDING BLOCKS OF GAMIFICATION}

\section{To repeat our definitions from the beginning:}

Gamification drives participation and engagement by integrating game mechanics or game dynamics into a website, business service, online community, content portal, or marketing campaign. Gamification is an emerging marketing discipline that provides a means of influencing the behavior of people online. It borrows key concepts from a number of related areas, including game design, customer loyalty programs, behavioral economics, and community management.

Game mechanics are the rules and rewards that that make up game play - the aspects that make it challenging, fun, satisfying, or whatever other emotion the game's designers hope to evoke. These emotions, in turn, are the result of desires and motivations we call game dynamics.

\section{Game Mechanics Motivate Behaviors}

The addition of game mechanics to a site or application allows you to layer compelling user experiences into existing activities. These gamified activities satisfy basic human desires, creating the addictive user experiences that motivate users to take certain actions. But what are these game mechanics?

Game mechanics are tools, techniques, and widgets that are used as building blocks for gamifying a website or application. Using them individually or together, it's possible to build a highly motivational user experience around existing website functionality or content. Some of the most common game mechanics include the following:

\section{Points}

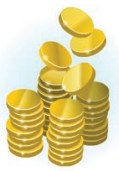

People love points. They love to earn them and to achieve them. This makes points incredible motivators. Points can be used to reward users across multiple dimensions, and different categories of points can be used to drive different behaviors within the same site or application. Points can also be used as status indicators, users can spend them to unlock access to content, or spend them on virtual goods and gifting. Studies done at IBM Research and the University of Chicago describe the dramatic effect that earning points can have on user behavior, even if there's no monetary value associated with them. People just love to be rewarded and feel like they've gained something

Levels

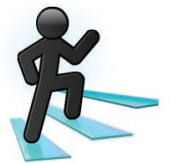

Levels are different classes in frequent-flyer programs, colored belts in martial arts, job titles in industry: an indication that you've reached a milestone, a level of accomplishment in a community and should be afforded a certain amount of respect and status. Levels are often defined as point thresholds, so that users can automatically level up based on their participation, or use levels to indicate status and control access to content on the site.

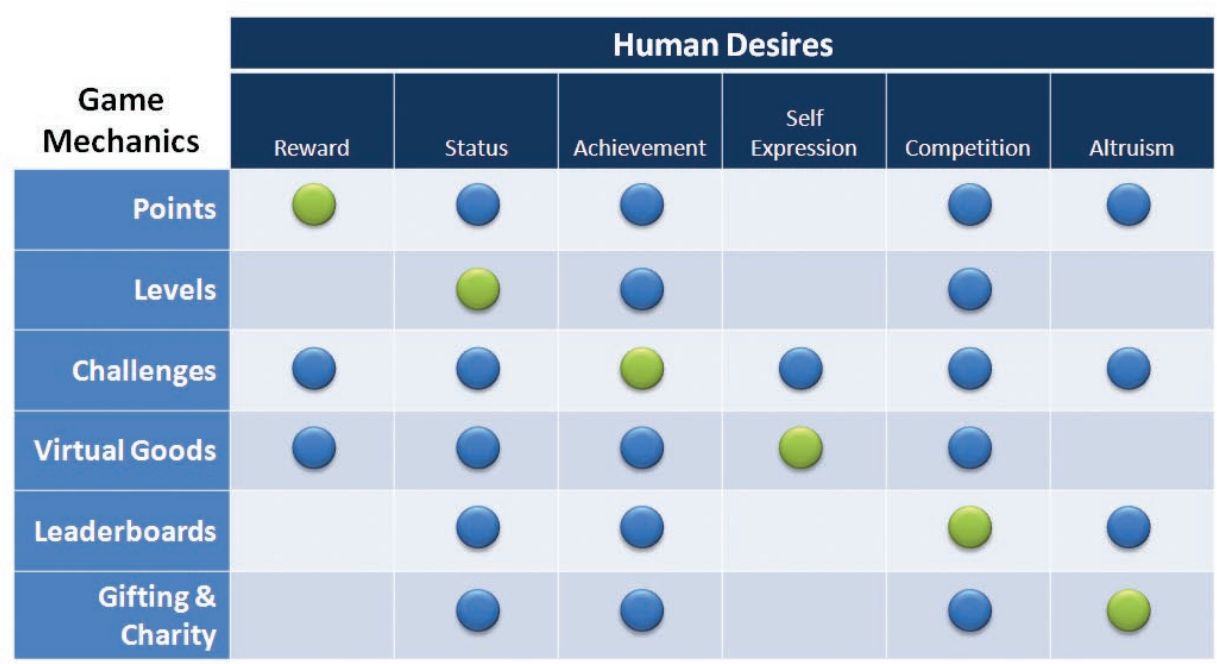

Figure 1 illustrates the interaction of basic human desires and game play. The green dots signify the primary desire a particular game mechanic fulfills, and the blue dots show the other areas that it affects. 


\section{Challenges, Trophies, Badges, Achievements}

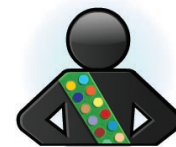

Challenges (aka trophies, badges, or achievements) give people missions to accomplish and then reward them for doing so. Challenges give people goals and the feeling like they're working toward something. The general approach is to configure challenges based on actions that you're tracking, and reward your users for reaching milestones with trophies, badges and achievements.

Trophies, badges, ribbons, etc. are the visible recognition of having reached new levels or completed challenges. One of the keys to making levels and challenges effective is providing a forum for them to show off their achievements, like a trophy case or user profile page that displays their badges. These have counterparts in the real world as well, as in Scouting merit badges, colored credit cards that indicate high spending limits, or colored frequent flyer cards that indicate member status.

\section{Virtual Goods}

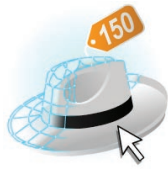

Virtual goods are non-physical objects that are purchased for use in online communities or online games. They have no intrinsic value and, by definition, are intangible. Virtual goods include such things as swords, coins, and potions, as well as digital gifts and digital clothing for avatars and virtual rooms. Virtual goods give your users a place to spend their points, a reason to want to earn, a way to buy each other gifts, and a way to self-express. Virtual goods can also be used as a revenue center, by selling users virtual goods for real dollars.

For a game economy to be effective over time, it helps to have a place to spend your points, a reason to want to earn more, and the ability to customize something that reflects your identity. Because that gets you invested, it gets you locked in, and it becomes a really great vector for creativity, competition, and self-expression in the community. You want your wall or virtual environment or avatar to look good, because all your friends can see it and compare it to theirs.

\section{Leaderboards}

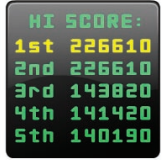

Most of the successful games ever created have wisely implemented a "high-score table." They bring aspiration, "fame," and your name in lights. They also indicate "how am I doing" against friends and against everybody else. In the context of gamification, leaderboards are used to track and display desired actions, using competition to drive valuable behavior.

\section{Competitions}

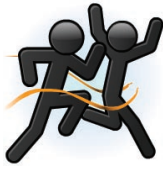

Competitions enable your users to challenge each other to get the high score at some activity. Once everyone has done the activity, the user with the highest score wins a reward while all the losers get a consolation prize.

This is great for "multiplayer-enabling" one-player games and other single user experiences. For example: "I just scored 500,000 points at Asteroids, I dare you to beat that!"

\section{Game Dynamics Satisfy Desires}

Why are people motivated by game mechanics? Because of game dynamics.

People have fundamental needs and desires - desire for reward, status, achievement, self-expression, competition, and altruism among others. These needs are universal, and cross generations, demographics, cultures, and genders. Game designers have known for years how to address these needs within gaming environments, and gamification now enables these precepts to be applied more broadly. By wrapping the appropriate set of game mechanics around your website, application, or community, you can create an experience that drives behavior by satisfying one or more of these human needs:

\section{Reward}

Human beings are motivated by receiving rewards - something of value given for some kind of action. A reward, tangible or intangible, is presented after the occurrence of an action (i.e., behavior) with the intent to cause the behavior to occur again. With gamification, the primary reward mechanism is through earning points or the equivalent (like frequent-flyer miles). But obtaining virtual goods, leveling up, and even completing achievements also satisfy this desire.

\section{Status}

Humans generally have a need for the esteem and respect of others, for status, recognition, fame, prestige, and attention. Status and esteem presents the normal human desire to be accepted and valued by others. People need to engage themselves to gain recognition, and have an activity or activities that give them a sense of contribution, to feel accepted and self-valued. All elements of game mechanics drive the status dynamic, but having achieved a higher level (such as getting a gold or platinum credit card) is the primary motivator. 
white paper

Gamification 101: An Introduction to the Use of Game Dynamics to Influence Behavior

\section{Achievement}

Some (but not all) people are motivated by a need to achieve, to accomplish something difficult through prolonged and repeated efforts, to work towards goals, and to win. People motivated by achievement tend to seek out challenges and set moderately difficult (but achievable) goals. Their most satisfying reward is the recognition of their achievements.

\section{Self-expression}

Many people want and need opportunities to express their autonomy and originality, to mark themselves as having unique personalities from those around them. This ties into the human desire to show off a sense of style, identity, and personality and to show off an affiliation with a group, or demonstrate a connection with a celebrity of some kind. Using virtual goods is a common way for players to create their own identity, whether they are earned through rewards, received as gifts, or bought directly with real currency. A person's avatar can often serve as a rich focal point for expression, and some people update their Facebook profile picture more than once a day.

\section{Competition}

Individuals can also be motivated by competition. It has been proven that higher levels of performance can be achieved when a competitive environment is established and the winner rewarded. That's because we gain a certain amount of satisfaction by comparing our performance to that of others.

All elements of game mechanics tap into this desire, even selfexpression, but the use of leaderboards is central to display competitive results and celebrate winners. Most all games provide at least a simple top ten list, and using that public display to indicate new levels achieved, rewards earned, or challenges met can be a great motivator to other players.

\section{Altruism}

Gift-giving is a strong motivator if you have a community where people seek to foster relationships. Not all gifts are equal, so in a world of free and commodity items, motivated gifters will seek out a more valuable form of expression, either through money or through time spent earning or creating the gift.

In gamification, gifting is an incredibly powerful acquisition and retention mechanic. You receive a gift from someone that pulls you into the game, and then you're incented to send gifts to all your friends, creating a great acquisition loop. And every time you receive a gift, it pulls you back into the application to redeem it, so it serves as a powerful retention vehicle as well. 
white paper

Gamification 101: An Introduction to the Use of Game Dynamics to Influence Behavior

\section{SUMMARY AND NEXT STEPS}

We've laid out a basic framework for gamification here: what it is, why it's powerful, and how companies are using it now. So what's next? Here are some brief starter questions to get clarity on before embarking on the gamification process.

\section{Questions to Ask}

As with any significant undertaking, there are many specific questions to answer as you think about applying gamification your situation:

\section{Is the Product Compelling?}

No matter the quality of the gamified experience, it is only a wrapper around your core offering. Gamification cannot make an unloved property into a hit, but it might provide the tipping point that helps a good product find a larger audience, or turns a hit into a cross-channel smash. Gamification works best when turning an exciting, attractive product into a richer, more participatory one.

\section{What is the Context?}

Will your audience discover your campaign on TV, in real-world stores, through social media channels, in print ads, or somewhere else? Does this connect a real-world experience with an online or mobile application? How will you early users help to grow your audience for you and through what means? Just as savvy advertisers connect TV, online, print, and other campaigns, consider how to extend the reach of the gamification process into other avenues.

\section{What Is the Timeframe?}

Gamification should be thought of as an extended process, and the most engaging games offer an experience that unfolds over time. This can be accomplished by making a deep and rich experience from the outset, or by evolving the experience over time, letting its audience build and drawing experienced users deeper into the game. Gamification is a long-term strategy, not a launch-and-forget-it one.

\section{Time to Market?}

How soon do you need to gamify your site or application? What level of effort will be required to do this? Do you have the resources to do it? Do you have the resources to support, operate, and enhance your gamification solution over time? What kind of expertise do you have in-house to make this happen? All of these questions will impact your ability to gamify your site in a timely manner.

\section{What Is Success?}

Most important is to have a clear sense of what your business goals are and how you'll go about determining if you've achieved them. This can be measured as strictly ROI, but there are other measures equally as valuable. 
white paper

Gamification 101: An Introduction to the Use of Game Dynamics to Influence Behavior

\section{ABOUT BUNCHBALL AND NITRO}

\section{Bunchball: The Industry Leader in Gamification}

Bunchball is the leading provider of online gamification solutions, used to drive high value participation, engagement, loyalty and revenue for some of the world's leading brands and media. Customers including Warner Bros, Comcast, Victoria's Secret PINK, USA Network, LiveOps, and Hasbro use Bunchball's Nitro gamification platform to create compelling, meaningful and enjoyable experiences for consumers, employees, and partners. Based in Silicon Valley and founded in February 2005, Bunchball's investors include Granite Ventures and Adobe Systems Incorporated. For more information, visit Bunchball online at www.bunchball.com.

\section{Nitro - The Participation Engine}

Nitro enables you to track and reward participation across the Internet by adding game mechanics to your websites, Facebook applications, and mobile applications. The Nitro solution includes the following:

\section{Proven Gamification Platform}

- Nitro, the industry's most scalable, reliable gamification platform.

\section{Expert Program Design Services}

- Build your own solution, or let us help you - we've created more Gamification solutions than the rest of the industry combined.

\section{Comprehensive Program Management Services}

- Strapped for resources? Let us manage your program.

\section{Advanced Analytics Services}

- Data-driven insights into user behaviors and how to drive them.

The Nitro gamification platform is a highly scalable and reliable Cloud-based service for gamifying websites, Facebook, Twitter, MySpace, and mobile applications - it has served over 80 million unique users and 4 billion transactions to date. Nitro's flexible architecture enables our customer's engineering teams to get up and running quickly, while our powerful administration tools empower the site production and marketing teams with real-time control over online user behavior. The platform delivers the industry's most comprehensive set of game mechanics, including:
- Actions
- Virtual Goods
- Poker
- Challenges
- Virtual Rooms
- Comments
- Trophies
- Avatars
- Friends
- Badges
- Groups
- Facebook and Twitter Connector
- Achievements
- Competitions
- Points
- Real-time Notifications
- Levels
- Newsfeeds
- Leaderboards
- Trivia 


\section{bunchball.com}

We gratefully acknowledge the contribution of many others to the ideas outlined in this paper. In particular we would like to give special mention to Kathi Fox, Amy Jo Kim, Barry Kirk, and Gabe Zichermann. 